

\title{
AVALIAÇÃO DA EXTRAÇÃO POR SOLVENTES PARA OBTENÇÃO DO EXTRATO DE ESPINAFRE (TETRAGONIA TETRAGONIOIDES)
}

\author{
B. S. VALLE ${ }^{1}$, R. S. G. RIBEIRO ${ }^{1}$, V. F. SILVA $^{1}$, T. S. MARTINS ${ }^{1}$ e C. S. S. PEREIRA ${ }^{1}$ \\ ${ }^{1}$ Universidade de Vassouras, Engenharia Química \\ E-mail para contato: bianca.svalle.90@gmail.com
}

\begin{abstract}
RESUMO - A extração de óleos essenciais de plantas têm alavancado estudos científicos na área de compostos fitoquímicos com a finalidade da substituição dos produtos sintéticos. O espinafre (Tetragonia tetragonioides) é rico em compostos fenólicos, flavonoides, carotenoides, tocoferóis e antioxidantes. O objetivo deste trabalho consistiu no processo de extração para obtenção do extrato de espinafre utilizando metanol e etanol como solventes. As extrações ocorreram em um período de 4 horas. $\mathrm{O}$ rendimento obtido após o processo de extração foi de $46,2 \%$ para metanol e $10,5 \%$ para etanol. Os extratos foram analisados quanto ao perfil químico através da espectroscopia de infravermelho com transformada de Fourier. Os dados obtidos a partir dos espectros de infravermelho foram submetidos à análise de componentes principais apresentando um índice de similaridade de $60,8 \%$ entre os extratos obtidos com metanol e etanol.
\end{abstract}

\section{INTRODUÇÃO}

O espinafre encontrado no Brasil é proveniente da Nova Zelândia e possui como nome científico Tetragonia tetragonioides. Essa espécie possui folhas verde-escuras de formato triangular e é cultivada em climas quentes. É rico em compostos fenólicos, flavonoides, carotenoides, tocoferóis e antioxidantes. Devido aos seus benefícios ao organismo é muito estudado e utilizado como planta medicinal (Azevedo, 2012).

Diante do crescente interesse da indústria pela descoberta de novas substâncias, os óleos essenciais extraídos das plantas têm alavancado estudos científicos na área de compostos fitoquímicos com a finalidade da substituição dos produtos sintéticos frequentemente utilizados na indústria farmacêutica, química e alimentícia que são prejudiciais à saúde (Ehlert et al., 2006). Os óleos essenciais são compostos naturais compostos por substâncias aromáticas e voláteis produzidas pelas plantas. Possui princípios ativos de ação terapêutica para o organismo, sendo amplamente utilizado na indústria para diversas aplicabilidades. Sua extração pode ser realizada por diferentes técnicas como prensagem, destilação por arraste de vapor, fluido supercrítico e por solventes orgânicos (Wolffenbüttel, 2007).

A extração sólido-líquido é uma operação unitária cujo objetivo é extrair os compostos desejados de uma fase sólida através de sua transferência para uma fase líquida (solvente). Em um processo contínuo, com auxílio de aquecimento, o solvente é enriquecido de soluto enquanto que a amostra sólida se empobrece do mesmo. O solvente ideal é aquele que extrai 


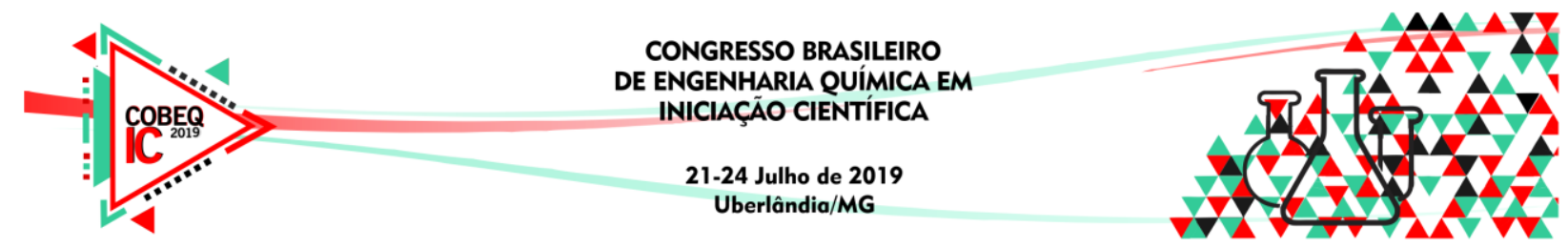

com qualidade os compostos desejados e apresenta um bom rendimento ao final da extração (Jardim, 2010; Trancoso, 2013).

A extração do óleo de espinafre (Tetragonia tetragonioides) foi estudada em 1979 por Vick e Zimmermann ao analisarem a presença de uma enzima catalisadora da síntese de ácido graxo. Em 1986, Calder et al., realizaram extrações utilizando metanol como solvente em plantas da Nova Zelândia em busca de antibióticos naturais e Bloor (1995) avaliou o uso do etanol na extração de compostos com atividades antivirais, citotóxicas e antimicrobianas do espinafre.

Com o intuito de avançar as pesquisas na área de química verde, este trabalho objetivou analisar o rendimento da extração do óleo de espinafre devido o mesmo apresentar propriedades antioxidantes com potencial substituição dos antioxidantes sintéticos.

\section{MATERIAL E MÉTODOS}

As extrações foram realizadas no laboratório de Engenharia Química da Universidade de Vassouras. A matéria prima utilizada foi adquirida em comércio local e utilizou-se na extração as folhas do espinafre (Figura 1).

Figura 1 - Folhas frescas de espinafre

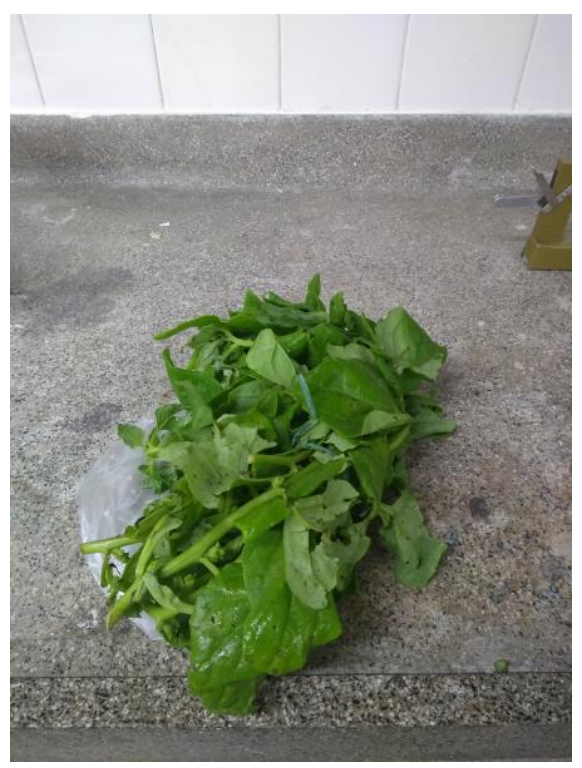

O processo de extração do óleo de espinafre foi realizado em triplicata em um aparato Soxhlet. Os solventes utilizados foram o metanol $(99,8 \%)$ e o etanol $(99,8 \%)$.

Para cada experimento de extração foram pesadas aproximadamente $40 \mathrm{~g}$ de matériaprima e colocados no extrator com uma razão de matéria-prima/solvente (massa/massa) de 1:14, sob temperaturas de extração de $70^{\circ} \mathrm{C}$. Foram fixados 3 ciclos de extração com duração entre 3 e 4 horas para cada amostra. $\mathrm{O}$ extrator foi montado de acordo com a Figura 2. 




Figura 2 - Extrator Soxhlet.

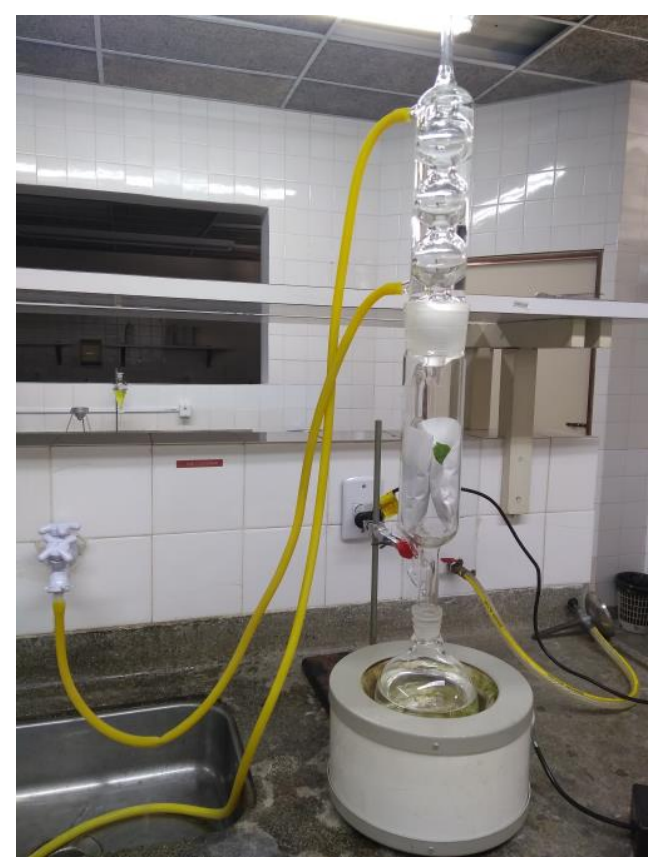

Após o processo de extração, a miscela (óleo + solvente) foi encaminhada a um evaporador rotativo para eliminação do solvente.

O rendimento mássico da extração de óleo (\%) foi realizado aplicando a Equação 1.

$$
\text { Rendimento em óleo }(\mathrm{Y})=\frac{\mathrm{m}_{2}}{\mathrm{~m}_{1}} \times 100
$$

onde: $\mathrm{m}_{2}$ e $\mathrm{m}_{1}$ são as massas de óleo extraídas e a massa de matéria prima utilizada nos experimentos, respectivamente

Os extratos foram analisados através da técnica de espectroscopia no infravermelho com transformada de Fourier, onde uma pequena quantidade do óleo de espinafre foi colocada sobre uma pastilha de $\mathrm{KBr}$, e assim, obtido um filme para determinação dos espectros.

\section{RESULTADOS E DISCUSSÃO}

As análises dos resultados foram realizadas através do rendimento do processo de extração e da espectrometria de infravermelho realizadas para os solventes etanol e metanol.

A Tabela 1 apresenta o rendimento médio obtido após as extrações para os dois tipos de solventes utilizados. 


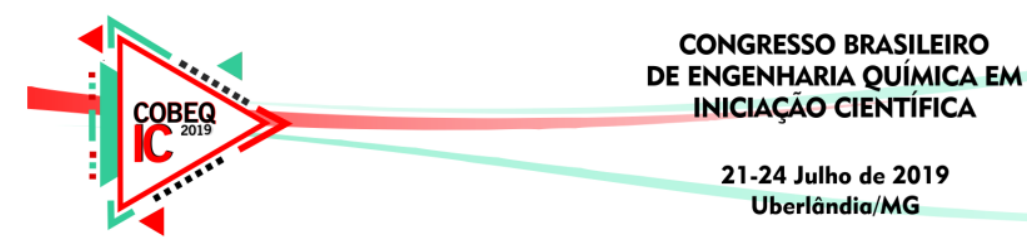

Tabela 1 - Rendimentos da extração do espinafre

\begin{tabular}{cccc}
\hline Solvente & $\mathbf{N}^{\circ}$ de ciclos & $\begin{array}{c}\text { Rendimento \% } \\
(\mathbf{g} / \mathbf{g})\end{array}$ & Desvio Padrão \\
\hline Etanol & 4 & 10,467 & 1,20 \\
Metanol & 4 & 46,167 & 3,11 \\
\hline
\end{tabular}

$\mathrm{Na}$ literatura não foram encontrados trabalhos que relatem o rendimento da extração do óleo de espinafre utilizando solventes como o metanol e o etanol. Os resultados encontrados no presente trabalho evidenciam a capacidade de ambos solventes na extração do óleo de espinafre, contudo o solvente de maior polaridade apresentou maior eficiência.

O metanol apresentou um rendimento 4 vezes maior, sendo seus ciclos mais rápidos devido ao seu ponto de ebulição $\left(64,5^{\circ} \mathrm{C}\right)$ se comparado com o etanol $\left(78,3^{\circ} \mathrm{C}\right)$. Em contrapartida, o metanol é tóxico e provém de fontes fósseis não renováveis. Apesar de possuir mais água em sua composição, o etanol busca competitividade por ser derivado de fontes renováveis, sendo também menos tóxico do que o metanol. $\mathrm{O}$ uso do etanol como solvente de escolha para extração de óleos essenciais torna-se vantajoso pelo baixo custo devido à sua produção em larga escala frente à variedade de fontes renováveis existente no Brasil.

O espectro no infravermelho do óleo de espinafre extraído com metanol e etanol são apresentados na Figura 3.

Figura 3 - Espectro no infravermelho dos extratos de espinafre extraídos com metanol e

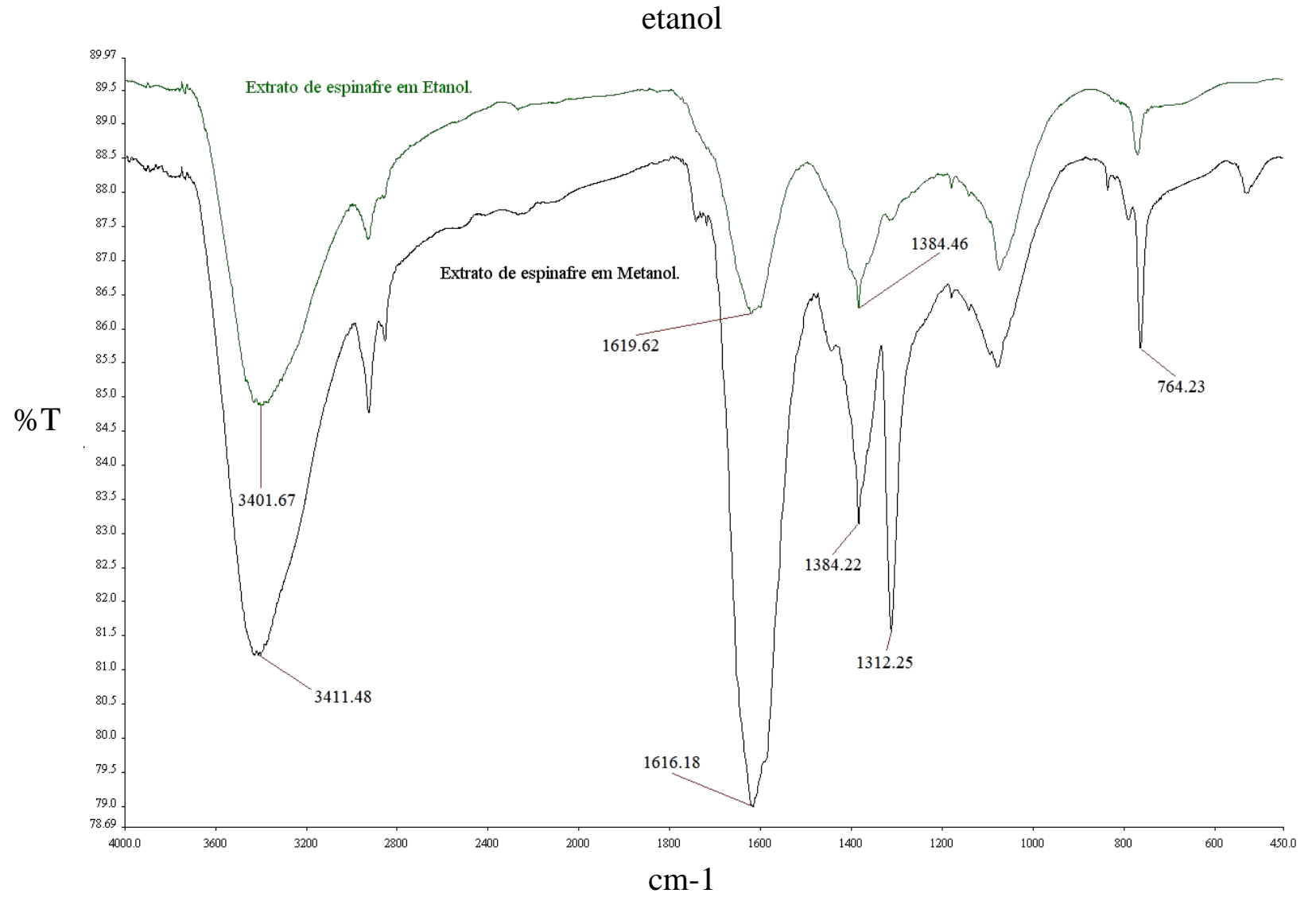




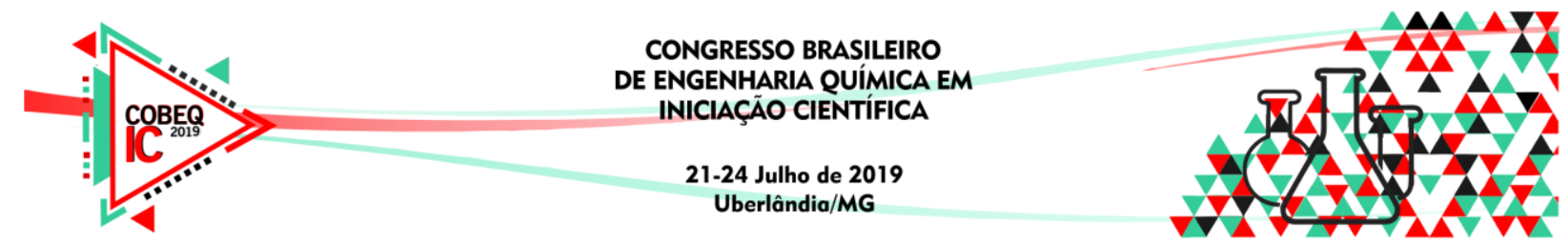

De acordo com o espectro apresentado, as amostras apresentam similaridade significativa em suas principais bandas de absorção. A banda localizada na região de 3540$3200 \mathrm{~cm}^{-1}$ e $1205-885 \mathrm{~cm}^{-1}$ é caracterizada pela presença de uma hidroxila $(\mathrm{C}-\mathrm{OH})$ ou de uma amina $\left(\mathrm{C}-\mathrm{NH}_{3}\right)$ sendo assim impossível apenas com o espectro infravermelho determinar qual grupo orgânico é responsável por essa banda intensa. A presença da hidroxila pode ser proveniente do solvente ou de compostos como os carotenóides, já se for uma amina provém de uma porfirina ou pirrol. A banda localizada na região de $1620-1575 \mathrm{~cm}^{-1}$ e $1430-1385 \mathrm{~cm}^{-}$ ${ }^{1}$ é caracterizada pela presença de uma carboxila $\left({ }^{-} \mathrm{O}-\mathrm{C}=\mathrm{O}\right)$ sendo possível predizer, mas não afirmar, que há a presença de um ácido carboxílico na estrutura do composto analisado, tendo compatibilidade com o grupamento das clorofilas.

Resultados semelhantes foram relatados por Castelo et al.(2010) que evidenciaram a presença da banda característica do grupamento hidroxila de álcoois $\left(3411-3443 \mathrm{~cm}^{-1}\right)$ e do grupamento cetona na região de $1700-1725 \mathrm{~cm}^{-1}$ para óleo essencial extraído de quatro espécies analisadas(Baccharis sp, Blepharocalyx salicifolius, Psidium myrsinites e Protium ovatum), sendo seus espectros no infravermelho um pouco semelhante. Pereira e Maia (2007) além de identificar a banda de absorção característica de hidroxilas em $3.512 \mathrm{~cm}^{-1}$, relataram uma possível deformação axial de $\mathrm{C}=\mathrm{C}$ de anel em 1.600 e $1.513 \mathrm{~cm}-1$ em folhas de Ocimum gratissimum L..

\section{CONCLUSÃO}

Pode-se concluir que o processo de extração das folhas do espinafre utilizando os solventes, etanol e metanol foram satisfatórios. O rendimento obtido após o processo de extração foi de 46,2\% para metanol e 10,5 \% para etanol. Apesar do menor rendimento, o uso de etanol merece destaque em substituição aos solventes derivados de petróleo. Para alcançar maiores rendimentos deve-se realizar novos estudos para otimizar o processo de extração. Os dados obtidos a partir dos espectros de infravermelho foram submetidos à análise de componentes principais apresentando um índice de similaridade de 60,8\% entre os extratos obtidos com metanol e etanol. Estudos de outras espécies de plantas presentes na literatura corroboraram os resultados encontrados com as bandas de absorção de grupamentos comuns encontrados no espectro. Contudo, novas análises deverão ser realizadas para identificar e quantificar os compostos bioativos presentes nos extratos de espinafre.

\section{REFERÊNCIAS}

AZEVEDO, F. L. A. A. Valor nutricional, capacidade antioxidante e utilização de folhas de espinafre (Tetragonia tetragonoides) em pó como ingrediente de pão de forma. $130 \mathrm{f}$. Tese (Doutorado em Ciência e Tecnologia de Alimentos) - Universidade Federal da Paraíba, João Pessoa, 2012.

BLOOR, S. J. Uma pesquisa de extratos de plantas nativas da Nova Zelândia para atividades biológicas selecionadas. New Zealand Journal of Botany, v. 33, n. 4, p. 523-540, 1995.

CALDER, V. L .; COLE, A. L. J.; WALKER, J. R. L. Compostos antibióticos de plantas da Nova Zelândia. III: um levantamento de algumas plantas da Nova Zelândia para substâncias antibióticas. Jorn. da Soc. Real da Nova Zelândia, v. 16, n. 2, p. 169-181, 1986. 




CASTELO, A. V. M.; MENEZZI, C. H. S.; RESCK, I. S.. Rendimento e análises espectroscópicas (RMN 1H, 13C; IV) da composição química dos óleos essenciais de quatro plantas do cerrado. Cerne, v. 16, n. 4, 2010.

EHLERT, P. A. D.; BLANK, A. F.; ARRIGONI-BLANK, M. F.; PAULA, J. W. A.; CAMPOS, D. A.; ALVIANO, C. S. Tempo de hidrodestilação na extração de óleo essencial de sete espécies de plantas medicinais. Rev. Bras. de Plantas Medicinais, Botucatu, v. 8, n. 2, 2006.

FONSECA, S. F.; GONÇALVES, C. C. S. Extração de pigmentos do espinafre e separação em coluna de açúcar comercial. Química Nova na Escola, n. 20, p. 55-58, 2004.

JARDIM, I. C. S. F. Extração em fase sólida: fundamentos teóricos e novas estratégias para preparação de fases sólidas. Scientia Chromatographica, v. 2, n. 1, p. 13-25, 2010.

PEREIRA, C. A. M.; MAIA, J. F. Estudo da atividade antioxidante do extrato e do óleo essencial obtidos das folhas de alfavaca (Ocimum gratissimum L.). Ciência $e$ Tecnologia de Alimentos, v. 27, n. 3, p. 624-632, 2007.

RODRIGUES, C. E. C.; ARACAVA, K. K.; ABREU, F. N. Análise termodinâmica e estatística do processo de extração de óleo de soja utilizando solvente renovável. Rev. Int. de Ciência e Tecnologia de Alimentos, v. 45, n. 11, p. 2407-2414, 2010.

SILVA, C. L. M. Obtenção de esteres etilicos a partir da transesterificação do oleo de andiroba com etanol. 64 p. Diss. (mestrado) - Universidade Estadual de Campinas, Instituto de Quimica, Campinas, SP, 2005.

TRANCOSO, M. D. Projeto Óleos Essenciais: extração, importância e aplicações no cotidiano. Rev. Práxis, v. 5, n. 9, 2013.

VICK, B. A.; ZIMMERMANN, D. C. Distribution of a fatty acid cyclase enzyme system in plants. Plant physiology, v. 64, n. 2, p. 203-205, 1979.

WOLFFENBUTTEL, A. N. Óleos essenciais. Inf. $C R Q-V$, ano XI, n. ${ }^{\circ} 105$, págs. 06 e 07 novembro/dezembro/2007. 